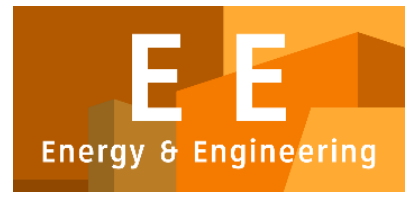

PAPER - OPEN ACCESS

\title{
Kajian Numerik Penguapan Pada Evaporator Desalinasi Air Laut Sistem Vakum Alami
}

\author{
Author \\ : Himsar Ambarita \\ DOI \\ : 10.32734 /ee.v1i1.117 \\ ISSN \\ : 2654-7031 \\ E-ISSN \\ : 2654-704X
}

Volume 1 Issue 1 - 2018 TALENTA Conference Series: Energy and Engineering

\section{(a) $(\mathbb{\theta})$}

This work is licensed under a Creative Commons Attribution-NoDerivatives 4.0 International License.

Published under licence by TALENTA Publisher, Universitas Sumatera Utara
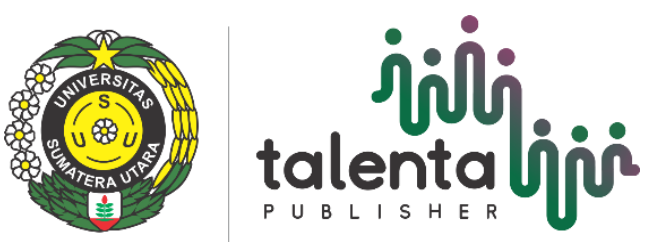
talenta

Available online at https://talentaconfseries.usu.ac.id

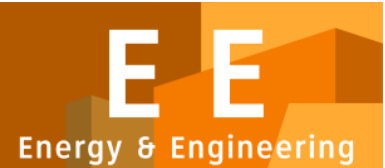

Energy \& Engineering

\title{
Kajian Numerik Penguapan Pada Evaporator Desalinasi Air Laut Sistem Vakum Alami
}

\author{
Himsar Ambarita* \\ ${ }^{a}$ Fakultas Teknik, Universitas Sumatera Utara, Medan 20155, Indonesia \\ himsar@usu.ac.id
}

\begin{abstract}
Abstrak
Fokus penelitian ini adalah alat desalinasi air laut energi surya dengan sistem vakum alami. Salah satu bagian terpenting yang menentukan performansi alat ini adalah proses penguapan pada kondisi vakum di dalam evaporator. Para peneliti umumnya menggunakan cara analitik dengan persamaan-persamaan empirik untuk menentukan laju penguapan pada evaporator.Padapenelitian ini diusulkan menggunakan metode numerik dengan menggunakan perangkat lunak CFD untuk menjelaskan proses penguapan pada evaporator. Hasil numerik dan analitik akan dibandingkan dengan hasil eksperimen. Peralatan eksperimen sederhana telah dirancang bangun untuk mendapatkan hasil eksperimen dan melakukan validasi. Hasil simulasi menunjukkan metode numerik dengan menggunakan perangkat lunak CFD dapat menggambarkan proses penguapan pada evaporator dengan baik. Perbandingan hasil analitik dan numerik menunjukkan laju penguapan di evaporator dengan metode numerik lebih dekat dengan hasil eksperimen. Metode numerik sebaiknya digunakan untuk melakukan inovasi agar dihasilkan peningkatan performansi desalinasi surya sistem vakum alami.
\end{abstract}

Kata Kunci: Desalinasi; Vakum Alami; Evaporasi; Numerik; Analitik;

\section{Pendahuluan}

Pemurnian air laut (Desalination) sudah lama dikenal dan digunakan umat manusia untuk memenuhi kebutuhannya akan air bersih. Saat ini, banyak daerah seperti di Timur Tengah, Negara-negara Arab, Amerika Utara, sebagian Asia, Eropa, Afrika, Amerikatengah, Amerika Selatan, dan Australia telah menggunakan sistem desalinasi air laut untuk memenuhi kebutuhan air bersih [3]. Di Indonesia pada beberapa daerah yang mengalami krisis air juga sudah menggunakan desalinasi air laut.

Sampaidengan saat ini para peneliti telah banyak mengajukan metode untuk melakukan desalinasi air laut. Antara lain adalah sistem multi-stage flash, multi-effects distillation, vapor compression,reversal osmosis,elektro-dialysis, dll.Sistem desalinasi air laut yang konvensional umumnya menggunakan energi yang berasal dari bahan bakar fosil. Berdasarkan suatu studi yang dilakukan oleh Kaligirou [6], sekitar 10.000 ton bahan bakar fosil dibakar setiap tahun untuk melakukan desalinasi. Oleh karena itu, sistem desa linasi termasuk sektor yang menghasilkan emisi Gas-gas 
rumah kaca yang cukup besar. Fakta ini telah mendorong para peneliti untuk melakukan inovasi agar desalinasi dapat bekerja lebih efisien dan juga menggunakan sumber energy terbarukan untuk menggantikan energy fosil [8].

Sumber energy terbarukan yang umum digunakan untuk melakukan desalinasi air laut adalah energy surya, angin, dan geothermal. Dari ketiga sumber energi terbarukan ini, yang paling banyak digunakan adalah energi surya, yaitu sekitar 57\% [3]. Berdasarkan kajian yang dilakukan, pada masa yang akan datang desalinasi air lautdengan menggunakan energi surya (disingkatdesalinasisurya) akan semakin banyak digunakan. Bahkan negara-negara yang kaya minyak seperti Arab Saudi sedang mengarahkan sumber energi pemurnian air lautnya agar memanfaatkan energi surya demi proses yang berkelanjutan. Proses pemanfaatan energi surya untuk desalinasi air lautdapatdilakukan secara surya termal dan atau secara hybridtermal-fotovol taik.

Salah satu metode desalinasi dengan memanfaatkan energi surya yang sangat potensial untuk diaplikasikan adalah alat desalinasi surya sistem vakumalami. Pada sistem ini, air laut dipaksa mengalami evaporasi pada tekanan yang vakum agar sumber energi panas pada suhu yang relatif rendah dapat digunakan. Energi surya yang dikumpulkan oleh kolektor surya pada temperatur rendah akan mempunyai efisiensi yang relatif tinggi. Maka penggunaan energi suryasebagai sumber energi desalinasi ini sangat cocok untuk diaplikasikan. Komponen utama desalinasi surya vakumini adalah evaporator dan kondensor. Gaya gravitasi air dimanfaatkan untuk mendapatkan kondisi vakum secara alami [1].

Meskipun sangat menjanjikan, penelitian tentang desalinasi surya dengan sistem vakum alami ini masih jauh dari tahap aplikasi. Penelitian tentang desalinasi ini masih terus mendapat perhatian dari para peneliti [4][5][9]. Salah satu fenomena yang harus diteliti lebih lanjut adalah proses penguapan (evaporasi) pada evaporator yang terjadi pada kondisivakum. Penelitian ini fokus pada kajian numerik penguapan pada evaporator. Perangkat lunak komersial Computational Fluid Dynamics (CFD) akan digunakan untuk melakukan simulasi proses penguapan. Hasil numerik dan analitik akan dibandingkan dengan hasil eksperimen. Hasil dari penelitian ini diharapkan akan memberikan kontribusi dalam meningkatkan performansi desalinasi surya sistem vakum alami.

\section{Metode dan Peralatan Eksperimen}

\subsection{Prinsip KerjaDesalinasiVakumAlami}

Prinsip kerjadesalinasi secara umum sangat sederhana. Air laut dipanaskan hingga menguap, dan kemudian uap yang dihasilkan dikondensasikan kembali dan ditampung di sebuah wadah. Air kondensat tersebut adalah air bersih. Sedangkan air laut yang tidak ikut menguap selama pemanasan menjadi konsentrat garam. Kondisi vakum di dalam sistem akan diperoleh dengan membangun sistem pada ketinggian $10.3 \mathrm{~m}$ untuk memanfaatkan gaya gravitasi air. Sistem yang sederhana dari desalinasi surya vakum alami ini ditampilkan pada Gambar 1.Sistem ini terdiri dari unit pemanas energi surya, evaporatordan kondensor dimana keduanya berada pada ketinggian $10 \mathrm{~m}$ di atas tanah. Evaporator dihubungkan dengan tangki air laut dan tangki air garam, sementara kondensor dengan tangki air bersih. Dengan kondisi seperti ini akan terjadi vakum di dalam evaporator. Air laut yang masuk ke evaporator akan mendidih dengan adanya panas dari solar kolektor atau sumber panas lain.

Sebagai catatan, tekanan uap dari air laut adalah sekitar 1,8\% lebih rendah dari tekanan uap air murni pada rentang suhu $0-100^{\circ} \mathrm{C}[1]$. Hal ini berarti jika bagian atas evaporator dan kondensor berada pada temperatur yang sama, karenaterhubung, maka air dari kondonser yang akan menguapdan diserap oleh air garam yang ada di evaporator. Dengan kata lain proses desalinasi tidak akan terjadi. Untuk menghindari hal ini, maka evaporator harus tetap diberi panas, sehingga air yang ada di dalam evaporator akan menguap dan mengalami kondensasi di kondensor. Setelah terjadi evaporasi, maka air garam akan terbentuk pada dasar evaporator dan akan turun kebawah dan berkumpul di tangki air garam. Karena temperaturnya masih tinggi, maka air garam yang panas ini akan dialirkan melalui sebuah alat penukar kalor, dan difungsikan untuk memanaskan air laut yang naik ke evaporator.Pada penelitian ini, untuk memudahkan mengontrol proses evaporasipada evaporator, digunakan pemanas listrik sebagai pengganti pemanas surya. 


\subsection{Analisis Evaporator}

Analysis sistem desalinasi vakum ini dapat dijelaskan pada bagian ini. Fungsi dari evaporator adalah sebagai ruang pemanasan air laut hingga sejumlah air laut dapat menjadi air bersih. Air laut akan masuk ke evaporator dari pipa pengumpan pada laju aliran massa yang disimbolkan $m_{\mathrm{i}}[\mathrm{kg} / \mathrm{s}]$. Di dalam evaporator akan terjadi penguapan dengan laju $m_{\mathrm{e}}[\mathrm{kg} / \mathrm{s}]$ yang akan mengalir dalam bentuk uap dan masuk ke kondensor. Sebagai sisanya akan terbentuk air garam yang akan keluar dari evaporator dengan laju $m_{\mathrm{w}}[\mathrm{kg} / \mathrm{s}]$.

Gambar 2 menampilkan diagram aliran pada evaporator. Pada saat terjadi penguapan diperlukan panas untuk menyuplai panas laten penguapan. Panas ini akan diambil darikolektor surya dan diantar oleh

fluida kerja yang laju alirannya disimbolkan dengan $m_{s c}$.

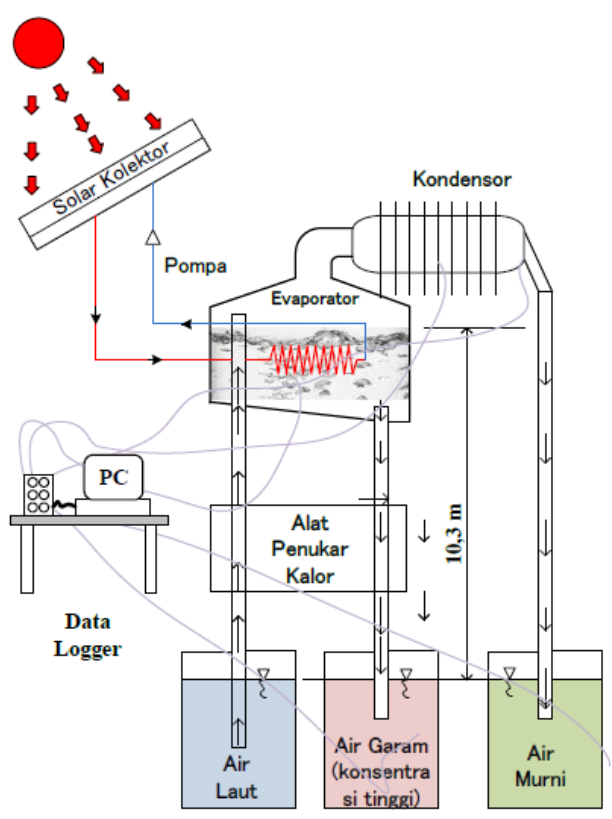

Gambar 1. Sistem desalinasi surya vakum alami

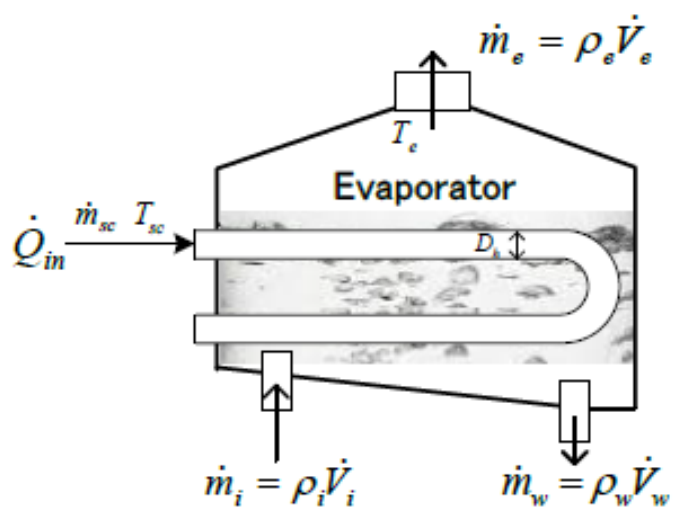

Gambar 2. Aliran massa dan energi di evaporator 
Hukum kekekalan massa akan memberikan Persamaan (1):

$$
\frac{d}{d t}(\rho V)_{s}=\rho_{i} V_{i}-\rho_{w} V_{w}-\rho_{e} V_{e}
$$

Jika konsentrasi dinyatakan dengan C [\%], maka perubahan konsentrasi garam di dalam tabung evaporator dapat dinyatakan dengan Persamaan (2):

$$
\frac{d}{d t}(\rho C V)_{s}=(\rho C)_{i} V_{i}-(\rho C)_{s} V_{w}
$$

Dimana huruf $s$ menyatakan air laut (seawater) yang ada di dalam evaporator. Hukum kekekalan energi akan memberikan Persamaan (3):

$$
\frac{d}{d t}\left(\rho C_{p} V T\right)_{s}=Q_{i n}+\left(\rho C_{p} T\right)_{i} V_{i}-\left(\rho C_{p} T\right)_{s} V_{w}-Q_{e}-Q_{\text {loss }}
$$

Laju penguapan (evaporasi) dari air laut di dalam evaporator (dinyatakandenganhuruf " $s$ ") kedalam air murni di kondensor (dinyatakan dengan huruf " $f$ ") dapat dirumuskan dengan menggunakan Persamaan (4) berikut:

$$
V_{e}=A_{\text {surf }} \frac{\alpha_{m}}{\rho_{f}} x\left[f\left(C_{s}\right) \frac{P\left(T_{s}\right)}{\left(T_{s}+273\right)^{0,5}}-\frac{P\left(T_{f}\right)+\Delta P}{\left(T_{f}+273\right)^{0,5}}\right]
$$

Dimana $A_{\text {surf }}$ adalah luas permukaan air yang ada di evaporator. Parameter $\alpha_{\mathrm{m}}$ adalah koefisien empiric yang diperoleh dengan cara eksperiment, menurut Bemporad (1995) nilainya $10^{-7} \leq \alpha_{\mathrm{m}} \leq 10^{-6}\left[\mathrm{~kg} / \mathrm{m}^{2}\right.$.Pa.s. $\left.\mathrm{K}^{0,5}\right]$. Beda tekanan evaporator dan kondensor disimbolkan dengan $\Delta P$. Persamaan (1) sampai dengan Persamaan (4) adalah persamaan analitik yang umum digunakan dalam analysis desalinasi surya sitem vakum alami. Pada penelitian ini, Computational Fluid Dynamic (CFD) akan digunakan untuk menganalisis laju evaporasi sebagai pengganti Persamaan (4).

\subsection{Peralatan Eksperimen}

Pada penilitian ini satu unit desalinasi surya sistem vakum alami akan dirancangbangun. Evaporator terbuat dari stainless steel 304 seperti ditampilkan pada Gambar 3. Material evaporator mempunyai ukuran dengan bagian bawah berbentuk silinder dengan ukuran diameter $250 \mathrm{~mm}$, tinggi $150 \mathrm{~mm}$ dan tebal $5 \mathrm{~mm}$ serta bagian atas berbentuk kerucut dengan ukuran diameter bawah $250 \mathrm{~mm}$, diameter atas $12,7 \mathrm{~mm}$ dan tebal $3 \mathrm{~mm}$ yang disertai dengan pemanaslistrik yang memiliki ukuran diameter $50 \mathrm{~mm}$ dengan panjang $2400 \mathrm{~mm}$. Temperatur pada evaporator diukur dengan menggunakan termokopel tipe $\mathrm{J}$ dengan akurasi $0,1^{\circ} \mathrm{C}$ dan direkam dengan menggunakan Agilent Data logger. 


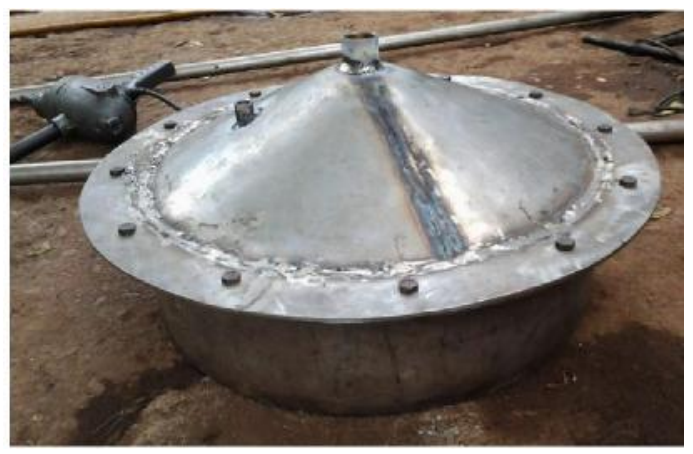

Gambar 3. Evaporator sebagai alat eksperimen

\subsection{Computational Fluid Dynamics(CFD)}

Proses simulasi dilakukan dengan dengan menggunakan perangkat lunak komersial CFD. Daerah perhitungan (Computational Domain) yang akan digunakan pada penelitian ini hanyalah evaporator, seperti yang ditampilkan pada Gambar 4(a). Bentuk meshing yang digunakan juga ditampilkan pada Gambar 4(b).

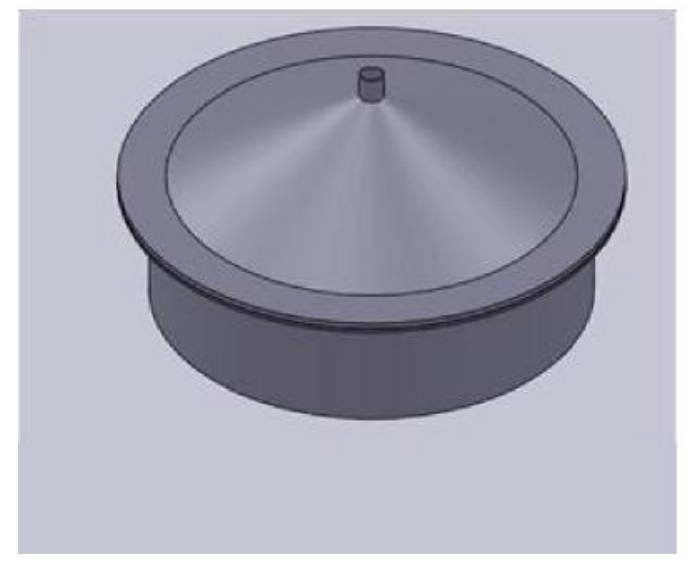

(a) Computational Domain

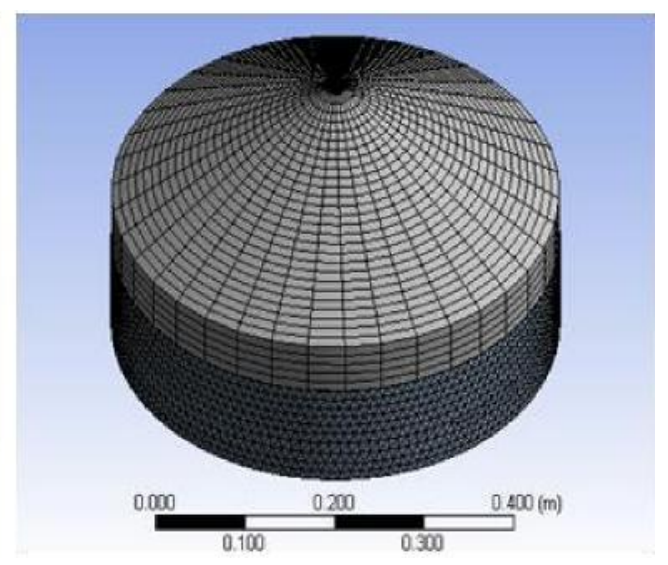

(b) Meshing

Gambar 4: Geometri evaporator

Tabel 1: Kondisi dan nilai batas

\begin{tabular}{lll}
\hline Kondisi Batas & Jenis & Nilai \\
\hline Air Laut & Fluid & $\rho=1023,475 \mathrm{~kg} / \mathrm{m}^{3}$ \\
& & $\mathrm{Cp}=4001.45 \mathrm{~J} / \mathrm{Kg}-\mathrm{K}$ \\
& & $\mathrm{k}=0.6085 \mathrm{~W} / \mathrm{m}-\mathrm{K}$ \\
Pemanas & Solid & $\mu=0.969 \mathrm{~kg} / \mathrm{m}-\mathrm{s}$ \\
& & $\rho=8060 \mathrm{~kg} / \mathrm{m}^{3}$ \\
& & $\mathrm{Cp}=530 \mathrm{~J} / \mathrm{Kg}-\mathrm{K}$ \\
Outlet & Pressout & $\mathrm{k}=17 \mathrm{~W} / \mathrm{m}-\mathrm{K}$ \\
Dinding & Wall & - \\
\hline
\end{tabular}




\section{$\mathrm{Cp}=530 \mathrm{~J} / \mathrm{Kg}-\mathrm{K}$ \\ $\mathrm{k}=17 \mathrm{~W} / \mathrm{m}-\mathrm{K}$}

Persamaan pembentuk aliran yang digunakan pada simulasi ini adalah persamaan 3D.Masing-masing persamaan adalah:

Persamaan kontinuitas oleh Persamaan (5):

$$
\frac{\partial \rho}{\partial t}+\frac{\partial}{\partial x_{i_{s}}}\left(\rho u_{i}\right)=0
$$

Persamaan momentum oleh Persamaan (6) :

$$
\frac{\partial\left(\rho u_{i}\right)}{\partial t}+\frac{\partial\left(\rho u_{i} u_{j}\right)}{\partial x_{i}}=-\frac{\partial \rho}{\partial x_{i}}+\frac{\partial}{\partial x_{j}}\left[\mu_{e f}\left(\frac{\partial u_{i}}{\partial x_{j}}+\frac{\partial u_{j}}{\partial x_{i}}\right)-\frac{2}{3} \delta_{i j} \mu_{e f} \frac{\partial u_{k}}{\partial x_{k}}\right]+\rho f
$$

Persamaan energi oleh Persamaan (7):

$$
\frac{\partial(\rho C T)}{\partial t}+\frac{\partial(\rho C T)}{\partial x_{i}}=\frac{\partial}{\partial x_{i}}\left(k \frac{\partial T}{\partial x_{i}}\right)-p \frac{\partial u_{i}}{\partial x_{i}}+\rho \dot{q}+\Phi
$$

dimana $i, j$, dan $k \square 1,2$, dan 3 masing-masing menyatakan sumbu $x, y, z$. Model multi fasa Eulerian digunakan untuk memodelkan proses kondensasi dan evaporasi. Kondisi dan nilai batas yang digunakan pada simulasi numerik ditampilkan pada Tabel 1. Algoritma SIMPLE digunakan untuk menggabungkan medan kecepatan dan medan tekanan. Persamaan momentun didiskritisasi dengan mengunakan second order upwindscheme.

\section{Hasil dan Diskusi}

Simulasi dan pengujian telah dilakukan pada evaporator ini dengan membuat temperatur air di dalam evaporator dijaga konstan pada $50^{\circ} \mathrm{C}$. Pengujian dilakukan selama 6 hari. Pada tulisan ini, hanya hasil 3 hari yang ditampilkan.

Perbandingan temperatur pada bagian dasar evaporator yang diperoleh dari hasil pengujian selama 3 hari dan hasil simulasi ditampilkan pada Gambar 5. Posisi pengukuran yang ditampilkan adalah sebuah titik tepat pada permukaan dasar evaporator. Temperatur hasil eksperimen relatif sama untuk ketiga hari percobaan. Sementara hasil simulasi menunjukkan sedikit perbedaan. Hal ini dikarenakan asumsi simulasi yang digunakan bahwa evaporator diisolasi sempurna. Sementara kondisi aktual, sebagian panas dari evaporator masih terbuang ke lingkungan. Secara umum dapat dikatakan hasil simulasi tidak berbeda jauh dengan hasil eksperimen.

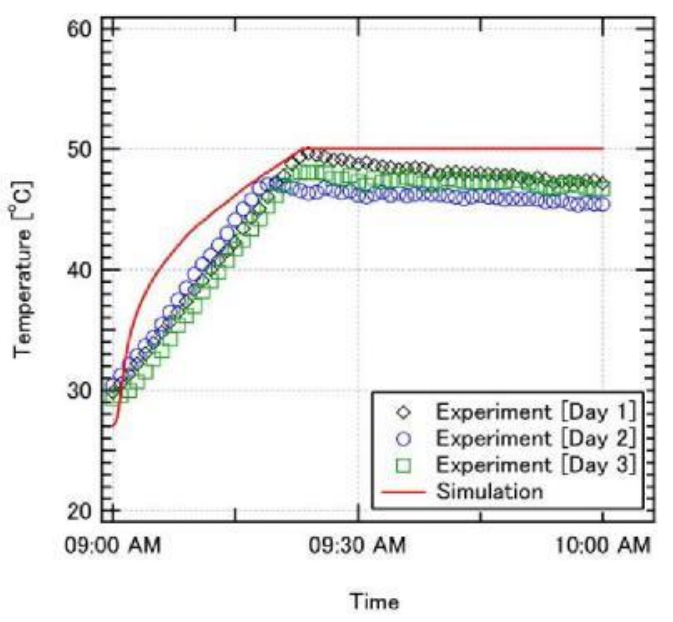

Gambar 5: Temperatur pada alas evaporator hasil pengujian dan simulasi

Pada gambar dapat dilihat bahwa, pemanasan sistem terjadi selama 20 menit pertama. Temperatur naik dari $30^{\circ} \mathrm{C}$ sampai $48^{\circ} \mathrm{C}$. Setelah itu temperatur akan konstan. Hal ini menunjukkan pada temperatur $50^{\circ} \mathrm{C}$ terjadi evaporasi. 
Karena terjadi perubahan fasa, maka panas yang diterima dari pemanas (electric heater) akan dipakai untuk panas penguapan dari fasa cair menjadi uap. Pada saat ini temperatur akan konstan dan proses penguapan berlangsung secara kontinu. Temperatur terjadinya perubahan fasa ini adalah sekitar $50^{\circ} \mathrm{C}$.Temperatur pada dinding evaporator dari hasil eksperimen dan hasil simulasi ditampilkan pada Gambar 6. Pada gambar dapat dilihat ada perbedaan antara hasil simulasi dan hasil eksperimen. Tetapi polanya masih tetap sama. Hal ini dikarenakan pada dinding evaporator kehilangan panas ke lingkungan cukup signifikan. Perbedaan ini perlu diperhatikan untuk mengurangikehilangan energi ke lingkungan dan membuat laju evaporasi tetap besar.

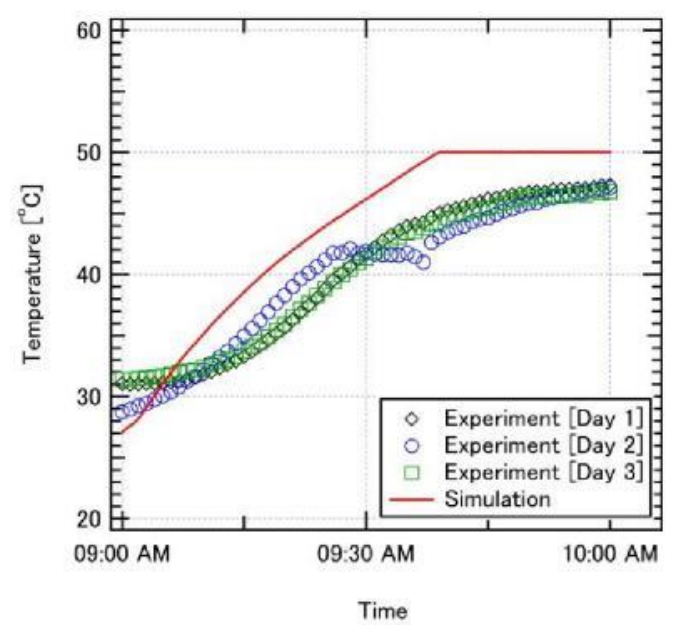

Gambar 6: Temperatur pada dinding evaporator hasil pengujian dan simulasi

Hasil simulasi dengan menggunakan perangkat lunak CFD ditampilkan dalam bentuk kontur fraksi cair dan kontur temperatur. Kontur fraksi cair di dalam evaporator pada menit ke 45 ditampilkan pada Gambar 7. Kontur ini diambil tepat pada pertengahan evaporator.
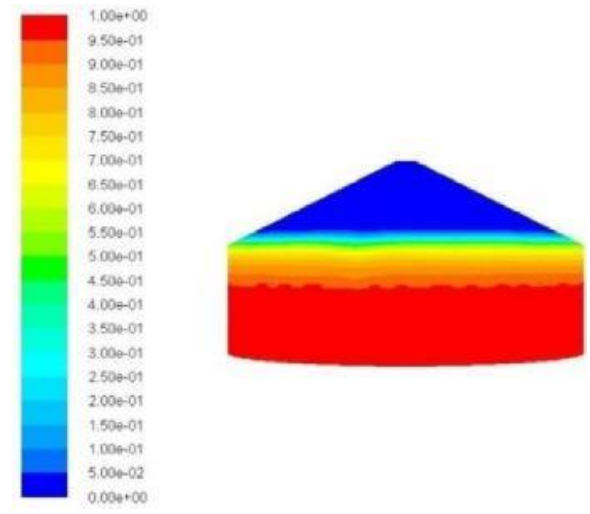

Gambar 7: Kontour Fraksi cair pada menit ke 45

Gambar 7 menunjukkan bahwa pada bagian bawah evaporator fraksi cair nilainya sama dengan 1, sementara pada bagian atas nilainya mendekati nol. Sementara diantara keduanya fraksi cair bervariasi di antara 1 dan 0 . Artinya air berangsur-angsur berubah menjadi uap dan akhirnya naik ke bagian atas sebelum bergerak menuju kondensor. Hasil simulasi ini menunjukkan bahwa proses evaporasi dapat disimulasikan dengan baik. 

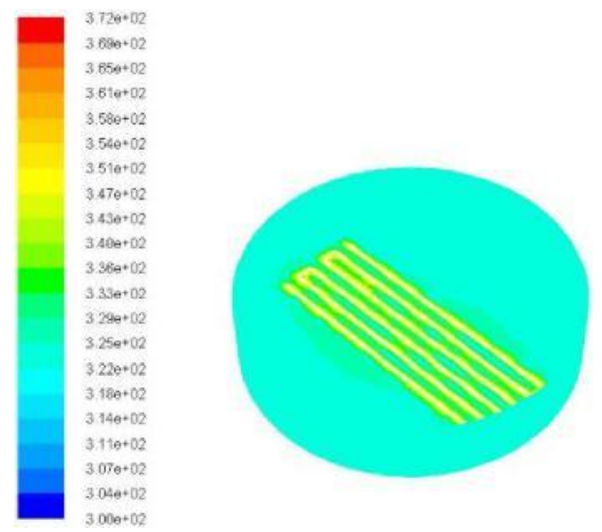

Gambar 8: Kontour Temperatur di dalam evaporator

Kontur temperatur di dalam evaporator pada menit yang ke 45 ditampilkan pada Gambar 8. Potongan gambar ini diambil pada bagian bawah evaporator dimana terdapat heater listrik. Temperatur di sekitar heater sangat tinggi sekitar $100^{\circ} \mathrm{C}$ sementara di bagian lainnya temperaturnya sekitar $50^{\circ} \mathrm{C}$. Fakta ini menunjukkan proses evaporasi terjadi pada temperatur $50^{\circ} \mathrm{C}$ atau jauh di bawah $100^{\circ} \mathrm{C}$. Hal ini bisa terjadi karena tekanan kerja evaporator ini dibuat pada vakum.

Analisis untuk mendapatkan laju penguapan dilakukan dengan cara analitik menggunakan Persamaan (4). Cara lainnya adalah menggunakan perangkat lunak CFD dan yang aktual dengan melakukan pengukuran. Pada penelitian ini setiap eksperimen dilakukan selama 8 jam. Volume air murni yang dihasilkan oleh desalinasi ini ditampilkan pada Tabel 2.Data pada tabel menunjukkan pendekatan dengan CFD memberikan hasil yang lebih dekat dengan hasil eksperimen.

Tabel 2:Volume air murni yang dihasilkan

\begin{tabular}{ll}
\hline Metode & Volume (Liter) \\
\hline Eksperimental & 1,20 \\
Analitik, Persamaan (4) & 0,97 \\
CFD & 1,02 \\
\hline
\end{tabular}

\section{Kesimpulan}

Pada penelitian ini telah dilakukan simulasi proses penguapan pada evaporator sebuahdesalinasi surya sitem vakum alami. Proses pemasukan panas kepada sistem diganti dengan pemanas listrik. Hasil simulasi menunjukkan perangkat lunak CFD dapat digunakan untuk melakukan simulasi proses penguapan dan hasilnya lebih dekat dengan eksperimen dibandingkan dengan pendekatan analitik yang umum dipakai. Metode ini disarankan untuk digunakan pada analisis desalinasi surya sistem vakum.

\section{Referensi}

[1] Al-Karabsheh S, Goswami DY. Analysis of an innovative water desalination system using low-grade solar heat.Desalination 156 (2003) 323-32.

[2] Bemporad, G. A., 1995, _Basic Hydrodynamic Aspects of a Solar Energy Based Desalination Process,“ Desalination, 54, pp. $125-134$.

[3] Eltawil MA, Zhengming Z, Yuan L. A review of renewable technologies integrated with desalination systems. Renew Sustain Energy Rev 13 (2009) 2245-62.

[4] Gude VG, Nirmalakandan N, Deng S, Maganti A. Low temperature desalination using solar collectors augmented by thermal energy storage. Appl Energy 91-1 (2012) 466-74. 
[5] Gude VG, Nirmalakandan N. Combined desalination and solar-assisted air-conditioning system. Energy Convers Manag 49 (2008) 332630.

[6] Kalogirou S., Seawater desalination using renewable energy sources. Prog Energy Combust Sci 31 (2005) $242-81$.

[7] Maroo SC, Goswami DY. Theoretical analysis of a single-stage and two-stage solar driven flash desalination system based on passive vacuum generation. Desalination 249 (2009) 635-46.

[8] Subramani A, Badruzzaman M, Oppenheimer J, Jacangelo JG. Energy mini-mization strategies and renewable energy utilization for desalination: a review. Water Res 45 (2011) 1907-20.

[9] Teoman A, H Al Madani. Feasibility study of renewable energy powered seawater desalination technology using natural vacuum technique. Renewable Energy 35 (2010) 506-514. 